\title{
Técnicas Microbiológicas para el Apoyo en el Proceso de Fermentación
}

\author{
Importance of Microbiological TeChNIQUeS \\ IN THE PRODUCTION OF ALCOHOL
}

\section{Zuluaga Castaño Jhoana Paulina}

Universidad Nacional Abierta y a Distancia- UNAD, Palmira, Colombia, pauli0901@gmail.com

Aprobado: 15/09/2011 - Aprobado: 15/12/2011

\section{RESUMEN}

Dentro del proceso de mejora continua de todas las industrias, con el fin de estar a la vanguardia y, más aún, siendo conocedores de todas las oportunidades de exportación e importación que hay hoy en día, la microbiología en la industria alcoholera genera grandes posibilidades de controlar pérdidas en su materia prima, optimizar el tiempo, comprender todo el ciclo durante la producción del alcohol y, en últimas y, teniendo en cuenta las variables, alcanzar una mayor calidad del producto final.

Por lo anterior, este artículo se centra en las técnicas de ayuda para obtener mayor rendimiento de la levadura en el proceso de fermentación, lo cual permitirá a los ingenieros encargados, conocer más a fondo el comportamiento de su materia prima; esto les facilitará encontrar el tratamiento y manejo adecuado, con el fin de mejorar la viabilidad de todo su clico y evitar o disminuir la contaminación, la cual es, finalmente, la que reduce la eficiencia de la materia prima, para el caso de la levadura.

Palabras clave: alcohol, contaminación, levadura, materia prima, microbiología

\section{ABSTRACT}

Within the process of continuous improvement across all industries and to be at the forefront and more being familiar with all import and export opportunities that exist today, microbiology in the alcohol industry generates great potential for control losses raw material, optimization of time, understanding of the whole cycle for the production of alcohol in last and taking into account the variables we have a better final product quality. That's why in this article we will focus on techniques to help get more out of the yeast in the fermentation process, allowing engineers to managers, better understand the behavior of its raw material, which will give the ease of finding appropriate treatment and management to improve the viability of all its acyclic and prevent or reduce pollution, who is ultimately reduces the efficiency of the raw material for the case of yeast. 


\section{InTRODUCCIÓN}

En muchas industrias de nuestro país se produce alcohol etílico, necesario para la elaboración de sus licores; por esto, cada una de ellas investiga sobre las variables más importantes que afectan el rendimiento en su proceso de fermentación de miel virgen, y ajustan, de paso, constantemente, todos los equipos del proceso con el fin de entregar mejor transformadas las materias primas, base para el proceso de producción de alcohol.

También las industrias se encargan de tener una cepa para su fermentación, utilizando para ello levaduras especializadas con alto grado de resistencia a concentraciones alcohólicas.

Finalmente, es importante reconocer que la fermentación de miel virgen es un proceso único que presenta variables difíciles de controlar, en especial lo referente al control y seguimiento de la transformación biotecnológica de la miel virgen a alcohol; esto ha generado múltiples inconvenientes en relación con la contaminación y la presencia de levaduras que no pertenecen a la cepa inicialmente sembrada, conocidas como levaduras salvajes, las cuales ocasionan mayores contaminantes denominados bastoncelos o bacillus. Dichos contaminantes ocasionan pérdidas de materias primas, que se representan en altos consumos de miel virgen para producir un litro de alcohol.

Además, se tiene en cuenta la integración de un proceso microbiológico concentrado en la evolución de la levadura durante la producción de alcohol, con base en los microorganismos acompañantes que puedan alterar su estabilidad, causándole estrés y disminuyendo su viabilidad.

Hoy en día, con los desarrollos de Brasil en relación con la producción de alcohol, las industrias quieren estar a la par con las nuevas técnicas y mejorar sus procesos en las destilerías. La Industria Licorera de Caldas -ILC- en busca de estos nuevos avances y con el fin de destacar y mejorar su proceso de control en la producción de alcohol, en el año 2007envió a las instalaciones de la firma Fermentec en Brasil, en el año 2007, a sus ingenieros, en el año 200 , quienes trajeron una nueva técnica, que hasta el momento, en el ámbito nacional, no ha sido aplicada.

\section{Marco Teórico}

Leveau y Bouix [1] establecieron en su Alcohol Texbook que en las destilerías se han encontrado microorganismos contaminantes como: LacotaciIlus sp, Sporolactobacillus sp, Zymomonas sp, Micrococcus sp, Acetobacter sp y Guconobacter sp.

Fajardo C. et al. [2] aisló bacterias ácido lácticas de las melazas de caña con el objetivo de estudiar la factibilidad de producción de ácido láctico por fermentación directa de la sacarosa. Obtuvo cuatro crecimientos bacterianos, de los cuales se describieron características generales típicas como, morfología celular, colonial, coloración de Gram, presencia de catalasa y la fermentación de azúcares (glucosa y fructuosa).

Madigan $\mathrm{M}$ et al. [3] realizaron un estudio para la determinación de las bacterias contaminantes en el proceso de producción de alcohol etílico y su relación con la floculación de la Saccharomyces cerevisiae. Inicialmente, se realizaron muestreos con el fin de estandarizar la metodología a nivel de laboratorio e identificar los contaminantes bacterianos en la melaza y la levadura productora de etanol.

Los resultados indicaron que los microorganismos contaminantes en el proceso analizado fueron: Lactobacillus sp. en un nivel promedio de $10 \times 10^{5}$ UFC/ml, y Zymomonas mobilis en un nivel promedio de $10 \times 10^{2} \mathrm{UFC} / \mathrm{ml}$.

El proceso de fermentación se produce por la acción de enzimas que conducen cambios químicos y físicos en las sustancias orgánicas. Aproximadamente, el $96 \%$ de la fermentación 
del etanol se lleva a cabo mediante cepas de Saccharomyces cerevisiae o especies relacionadas; el etanol se produce en la ruta de Embden-Meyerhof-Parnas (EMP) [4].

Las levaduras son la materia prima esencial. La palabra levadura hace pensar inmediatamente en "fermentación", por el hecho de que las dos expresiones, a menudo, han sido asociadas a lo largo de la historia. Sin embargo, se puede considerar que el desarrollo del concepto de levadura empezó alrededor del año 1680 [5] aunque después de los estudios llevados a cabo por el genio Pasteur, en 1876, se le dio la tipificación de individualidad como un organismo vivo, con sus propias características [6].

En el proceso de la fermentación que se realiza en la producción de alcohol se presenta la contaminación bacteriana, generalmente con formación de algunos compuestos, entre estos, ácidos orgánicos, los cuales inhiben la función de la levadura y generan metabolitos que imparten indeseables propiedades a los productos finales [7]. Esto, porque a través del metabolismo y de los nutrientes adicionales que se generan, entran las levaduras y los bacillos a competir por la alimentación; es así como se da inicio a la producción de bacterias o levaduras no deseables, pues cambian para adquirir su alimentación y poderse mantener en el medio.

Por lo anterior, la firma Fermentec ha introducido en su metodología técnicas que ayudan a darle confianza al proceso de fermentación y producción de alcohol. En Colombia, la primera industria en implementar dichas técnicas, ha sido la Industria Licorera de Caldas, hoy en día pionera en los siguientes procesos:

\section{A. Método de determinación de la viabilidad celular de levaduras}

La observación de la levadura comprende el recuento celular. Se realiza la determinación de la viabilidad a través del uso de eritrosina. El porcentaje de células viables, el porcentaje de reproducción y la población en millones/ml se determina transfiriéndose una muestra ya colorida para la cámara de Neubauer, donde serán contadas en 100 retículos, utilizando el objetivo de 10x para enfocar, y preferiblemente realizar el conteo en el objetivo de 40X [8].

Los resultados se basan en la verificación de las condiciones actuales de la fermentación, con lo cual se busca tener mayor precisión en los datos obtenidos finalmente. De acuerdo con lo anterior, la determinación de la levadura en todos sus aspectos de viabilidad se consigue a través del procedimiento con eritrosina, en el cual tenemos que:

La viabilidad es el porcentaje de células en actividad en la población de levaduras de la muestra elegida para ser evaluada; para tal fin, se manejan valores de rechazo de un mínimo del 50\% [16].

La reproducción son las levaduras que se encuentran en multiplicación, con un rango de referencia de $20 \%$ al $60 \%$ [16].
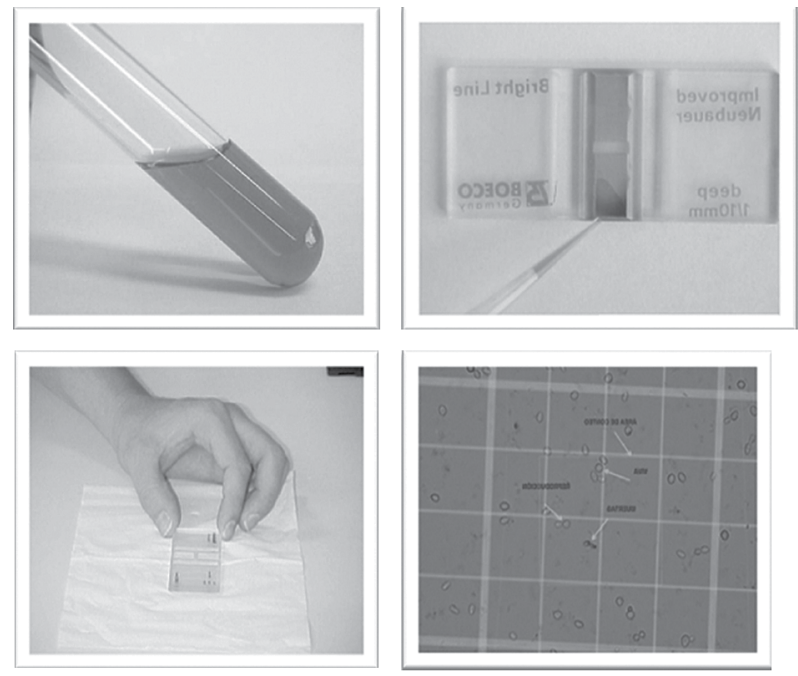

Fig. 1 Viabilidad de la levadura. Zuluaga, 2011 [8]

\section{B. Método para el cálculo de bacterias Cuantificación de la contaminación}

Se aplica el método para el cálculo de bacterias al microscopio óptico, con el fin de determinar la población de bastoncillos/ml presentes en las fases más importantes de la fermentación, como la alimentación, cuba 354 y la recuperación del proceso. Con lo anterior, se consigue obtener 
el cálculo de bastones, que da mayor precisión en la prueba, la cual, finalmente, es mucho más confiable cuando el número de bastoncillos $/ \mathrm{mL}$ de la muestra está entre $10^{6}$ y $10^{7}$, [8].

Para la implementación del método se usa azul de nilo y azul de metileno, pasando por un proceso de estabilización de 24 horas antes de ser utilizado. Se determina que para ser viable debe existir un número no mayor de 3 a 5 bastones por campo. Así mismo, que las células viables no presentan coloración, mientras que las no viables se encuentran teñidas con el colorante [8].

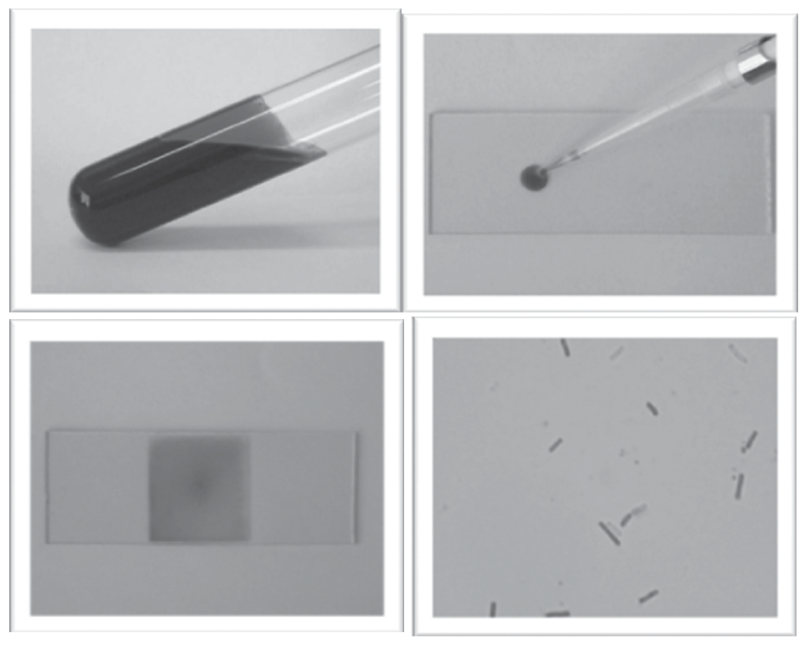

Fig. 2 Tinción de células. Zuluaga 2011 [8]

\section{Prueba de sensibilidad de bacterias a agen- tes antimicrobianos por espectrofotometría}

La prueba consiste en evaluar la acción de los antimicrobianos, como antibióticos y otros compuestos, a través de la lectura espectrofotométrica de la densidad óptica (absorbancia) de una suspensión microbiana, incubada con o sin el producto en prueba.

Es una metodología relativamente simple de realizar y permite, de cierta forma, indicar el producto más eficaz y/o la dosis que se ha de emplear dentro de un período relativamente corto $(6$ a 8 horas), lo que vuelve la utilización de los antimicrobianos más económica y racional.
Estandarizando esta metodología se está garantizado la posibilidad de manejar la contaminación presente en la fermentación, de acuerdo con la cuantificación de la contaminación que se hace de manera previa.

Se utiliza un testigo y la cantidad de tubos según los antibióticos que se quieran evaluar; estos contendrán medio de cultivo específico para el proceso; además, se tiene en cuenta la Cicloxamida, que es un inhibidor de la levadura y, finalmente, se realiza una lectura inicial y otra final.

Adicionalmente, se establece cómo la cuantificación de la contaminación es determinante para saber en qué momento el proceso requiere de antibióticos y se debe entrar a evaluarlos.
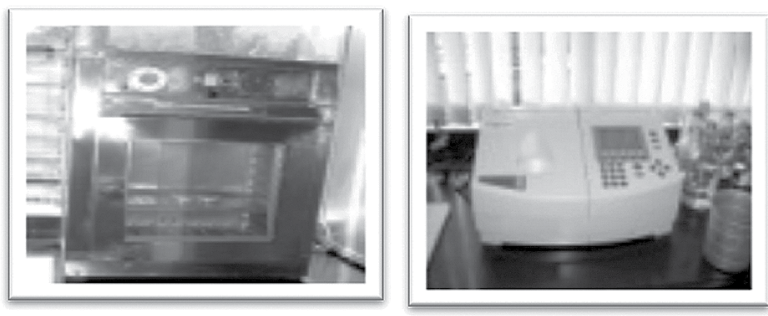

Fig. 3 Cuenta colonias. Zuluaga, 2010

Los lactobacilos son células de forma alargada, tolerantes en condiciones ácidas. Una muy importante diferencia, sin embargo, es el absoluto requerimiento de oxígeno de las bacterias acéticas. Los miembros del grupo son oxigénicas estrictas. Esto elimina la contaminación potencial por las oxigénicas fermentativas [12].

Fecmentec es una empresa especializada en fermentación alcohólica y control de laboratorio para la producción de azúcar y alcohol, que ha desarrollado nuevas metodologías y tecnologías para el sector industrial, ayudando, de esta manera, a mejorar los procesos productivos de las industrias desde el control y monitoreo de los microorganismos presentes en el proceso; de ahí la importancia de estas técnicas y su implementación. 


\section{Resultados y Análisis}

Habitualmente, la calidad se ha definido como el nivel de conformidad que mantiene un producto de acuerdo con sus especificaciones. Esta calidad es la que se puede generar y controlar dentro de cada industria, logrando de esta manera acreditar un producto cuya personalidad se caracteriza por una serie de medidas,: unas de orden legal y otras típicas del proceso, tales como los controles físico-químicos [8] organolépticos y microbiológicos [2], [12], [14]; por esto, teniendo en cuenta las normas o parámetros que rigen cada uno de los productos [13], y que definen con exactitud la calidad que finalmente se debe alcanzar $y$, así mismo, partiendo de las variaciones que se pueden encontrar, el control microbiológico constante y correcto es una necesidad en el proceso de fermentación.

De acuerdo con esto y con las técnicas que se desarrollaron para algunas de las fases determinantes del proceso, y partiendo de la viabilidad de la levadura y su comportamiento en el proceso, para limitar la presencia de contaminantes, que terminan afectandolo, se hace imprescindible impedir, entre otros, la presencia de patógenos y de contaminantes indeseables. Ambos aspectos, en especial el primero, se consigue mediante la pasteurización y otros sistemas de eliminación [9].

Sin embargo, para certificar y garantizar la inocuidad y viabilidad de la producción, se requieren distintos procesos de verificación y es precisamente en este punto donde se evalúa la calidad microbiológica del producto, y se determinan las condiciones en las cuales se desarrolla el proceso [10].

Finalmente, es importante recordar que un control de calidad microbiológico rutinario no resolverá necesariamente los problemas de contaminación. Sin embargo, ayudará a identificar el problema cuando este surja, con el fin de que puedan tomarse las medidas apropiadas para eliminar o por lo menos lograr controlar tal problema [11], [12], [15].

\section{Conclusiones}

Se debe tener en cuenta que la etapa de fermentación es el proceso que presenta más variables no controladas, en inconvenientes referidos a la contaminación y presencia de levaduras que no pertenecen a la cepa inicialmente sembrada, ocasionando con ello pérdidas de materias primas y altos consumos de miel virgen para producir un litro de alcohol.

Los aumentos de la eficiencia global en las plantas de producción de alcohol, se obtienen mediante el mejoramiento continuo del proceso; para ello, es necesario tener en cuenta las limitaciones que se pueden presentar. Por esa razón, los laboratorios de las industrias hoy en día se encuentran subvalorados, y han dejado de ser la guía para el desarrollo de la producción; es ahí, donde este artículo pretende tocar las fibras de la unión entre ingenieros, bacteriólogos y/o microbiólogos, con el fin de unir esfuerzos, para conocer y optimizar sus procesos a fondo, y evitar pérdidas en su producto final, para iniciar, de esta manera, la reutilización de los subproductos, y aumentar un mayor valor agregado.

Se invita a seguir los pasos de grandes empresas como Fermentec en Brasil, que hoy en día, tiene uno de los mejores modelos por seguir y cuyas técnicas ya son utilizadas en muchos países. Un ejemplo claro lo constituye en Colombia, la Industria Licorera de Caldas, que al implementar 3 de sus técnicas aplicadas y homologadas, evidencia la efectividad de las mismas, constituyéndose en una eficaz ayuda diagnóstica diaria para la producción de alcohol. 


\section{RefERENCIAS}

[1] Leveau Y.J., y Bouix M. (2000). Microbiología Industrial: los microorganismos de interés industrial. Editorial ACRIBIA, S.A. 3-88 y 529-559 p.

[2] Fajardo C. et al. (2008). Evaluación de melaza de caña como sustrato para la producción de Saccahromyce cereviseae. Pontificia Universidad Javeriana de Colombia. Facultad de Ciencias Básicas. Microbiología Industrial. Bogotá.

[3] Madigan M, Martinko J, \& Parker J. (2003). Biología de los Microorganismos. Madrid: Pearson Educación

[4] Ríos del Risco, C. A., Fajardo, M., Pérez M., J. C. (2005). Evaluación de una cepa de levadura para fermentar diferentes concentraciones de miel Apis mellifera. Estación Experimental Apícola de Cuba.

[5] Ramos, A. A. (2011). Proceso de Producción de Etanol y Control de Calidad Fábrica. Colombia. Feriva S.A, $28-30$ p.

[6] Zuluaga J. P. (2009). Control de Microbiología en el Proceso de Fermentación a través de Microscopia (Tesis de Grado). Universidad Católica de Manizales. 70 p.

[7] Socorras J.L. et al (2011). Indicadores de eficiencia en procesos fermentativos con miras al desarrollo de estrategias.

[8] Zuluaga J. P. (2009). Protocolo para el Control de Microbiología en el Proceso de Fermentación a través de Microscopia. Universidad Católica de Manizales. Pp. 47, 70.

[9] Vázquez, H. J. y Dacosta, O. (2007). Fermentación alcohólica: una opción para la producción de energía renovable a partir de desechos agrícolas. INGENIERÍA: investigación y tecnología VIII. 4. 249-259.2007.
[10] Palacios, LL. (2000). Fabricación de alcohol, (1ra Ed.). Salvad Editores S.A. Prácticas de Microbiología. (2011). Departamento de Microbiología y Genética Universidad de Salamanca. Disponible en la dirección electrónica: http://imb.usal.es/Practicas2/P2/ Practicas2.pdf

[11] Prescott C. S. y Dunn, C.G. (1992). Microbiología Industrial. Madrid: Aguilar 110-158 p.

[12] Sociedad Venezolana de Microbiología (2008). Sociedad Venezolana de Microbiología Apartado 76635. El Marqués, Caracas, Venezuela Universidad Nacional Experimental Francisco de Miranda, Coro, estado Falcón, Venezuela.

[13] Zamudio, T. (2005). Regulación Jurídica de las Biotecnologías. Equipo de Docencia e investigación UBA - Derecho. Recuperado el 10 de Octubre 2012 de http://www.biotech.bioetica.org/clase2-5.htm\#_ftn

[14] COPERSUCAR (2007). Manual de control microbiológico de usina de acucar e alcool. Caderno Copersucar. Serie industrial $N^{\circ}$ 005. Sao Paulo, Brasil.

[15] Scragg, A. (2008). Biotecnología para ingenieros. México: Limusa, 125 - 147 p.

[16] Tomasso, M. (2004). Tolerancia de las levaduras al etanol. Universidad de la República Uruguay. Facultad de Química. 